\title{
Changes in the distribution and structure of white-collar workers' residences in Japan during the period of modernization
}

\author{
Takashi Kirimura $^{\text {a }}$ \\ ${ }^{a}$ Department of Communication, Faculty of Letters, Kogakkan University, t-kirimura@kogakkan-u.ac.jp
}

Keywords: Company employees and executives, Telephone directory, Urban structure, Tokyo, Osaka, Kyoto

\begin{abstract}
:
In Japan, research on urban residential differentiation has been carried out since the 1970s. Most of this research has focused on large cities using social area analysis and factorial ecology. The poor availability of small area statistics hindered research on urban residential differentiation until the end of the 1960s. Therefore, previous studies that focused on the modern cities in Japan used region-specific materials. For example, Ueno (1981) who studied in Tokyo in the 1920s used the census data calculated by the Tokyo City Office and Mizuuchi (1982) who studied in Osaka from the 1860 s to the 1930 s used various statistics created by the prefectural police and so on. For this reason, it is difficult to explore the inter-city comparison on the residential differentiation during the period of modernization in Japan.
\end{abstract}

This study assesses the possibility of utilizing telephone directories as a data source to determine differences in geographical residence on the basis of occupation and visualize the distribution of white-collar workers' residences in the mid-1930s in three Japanese cities: Tokyo, Osaka, and Kyoto. Although the regional situation on the penetration of telephones needs to be considered, the inter-city comparison becomes possible since the telephone directories in which the occupation of telephone subscribers was recorded was made available nationwide in the pre-war period. Since the white-collar workers during that period relatively belonged to the high class, many of them were considered subscribing to telephones. In addition, white-collar workers changed the previous urban structure that consisted of merchants and craftsmen into a modern one. Therefore, white-collar workers are a suitable subject for analyzing the telephone directory and the residential differentiation in the mid-1930s.

According to the Burgess' concentric zone model, in the early twentieth century, the white-collar workers lived in the suburbs. It is also possible that their residences had spread the sectorial pattern along transportation routes considering Hoyt's sector model. Ueno (1981) says that in 1920, the residential districts in Tokyo comprised of civil servants and professional workers spread to the western region in a sectorial pattern. In Osaka, which is the second largest city in Japan, white-collar workers lived in the suburbs and also the center (Mizuuchi, 1982). In this study, we examine the distribution of residences among white-collar workers in the mid-1930s based on the results of the previous studies and population statistics related to white-collar workers in 1925 and 1965.

The telephone directories used in this study are "Syokugyou-betsu Denwa Meibo Dai 25 Han (Classified Telephone Directory of 25th Edition in Tokyo)" as of 1935, "Osaka-shi Oyobi Kinko Denwa Bango-bo (Telephone Directory of Osaka City and Suburbs)" as of 1937 and "Kyoto-shi Denwa Bango-bo (Telephone Directory of Kyoto City)" as of 1937. The white-collar workers registered in these directories were either "Kaisya-jyuyaku Oyobi Kaisya-in (company employees and executives)", "Ginko-jyuyaku Oyobi Ginko-in (bank employees and executives)", or "Kanri (clerical workers)". The data for analysis in the three cities were collected from the address information of only company employees and executives provided in the telephone directories. Moreover, being a company employee or executive was regarded as a typical occupation of white-collar workers. The spatial units chochos (small areas) in Tokyo and Osaka were considered. Since the address information in the center of Kyoto was insufficient, the units in only Kyoto were taken as census tracts. The number of telephone subscribers per 100 households in the 1935 Population Census was calculated by summing up the records of the subscribers on the basis of their spatial units. Table 1 shows the number of telephone subscribers among company employees and executives in the mid-1930s and the number of households in 1935 in Tokyo, Osaka, and Kyoto. 
Table 1. The number of telephone subscribers among company employees and executives in the mid-1930s and households in 1935 in Tokyo, Osaka, and Kyoto.

\begin{tabular}{c|cc}
\hline & $\begin{array}{c}\text { No. of Telephone Subscribers among } \\
\text { Company Employees and Executives }\end{array}$ & $\begin{array}{c}\text { No. of Households in } \\
\text { 1935 Population Census }\end{array}$ \\
\hline Tokyo & 9,702 (in 1935) & $1,186,169$ \\
Osaka & 1,904 (in 1937) & 623,659 \\
Kyoto & 1,037 (in 1937) & 222,445 \\
\hline
\end{tabular}

Figure 1 shows the distribution of telephone subscribers among company employees and executives in Tokyo, Osaka, and Kyoto. In Tokyo, there were not many white-collar workers in the old city center who had their origin from the townsmen's residences in the Edo period. Many of the white-collar workers lived in the western sector of the suburbs. Their residences spread not only in the specific sector of the suburbs but also in the old city center in Osaka and Kyoto. The distribution of the white-collar workers generally corresponded to the distribution of the salaried workers based on the 1925 Population Census by municipalities in the three cities. However, there was some difference in Tokyo since the salaried workers' residences also spread in the city center. It is assumed that the suburbanization of the white-collar workers had proceeded in the decade.

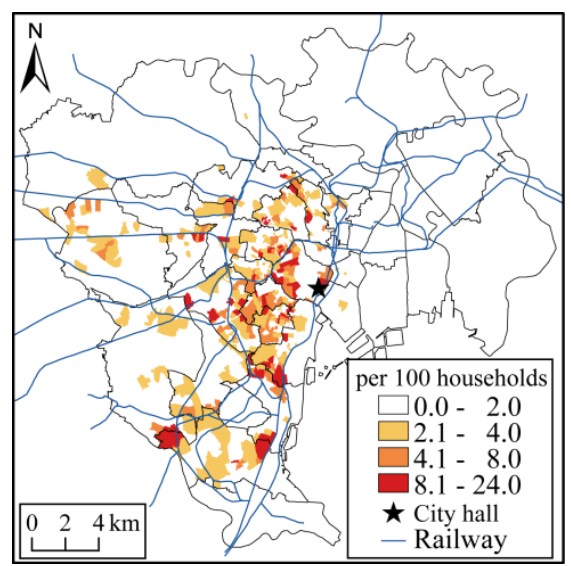

Tokyo (in 1935)

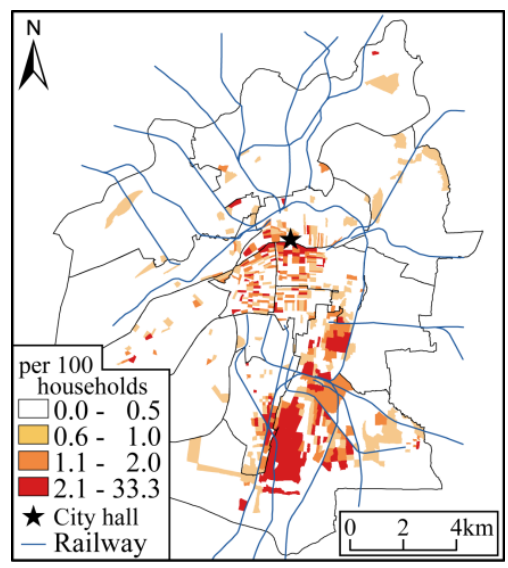

Osaka (in 1937)

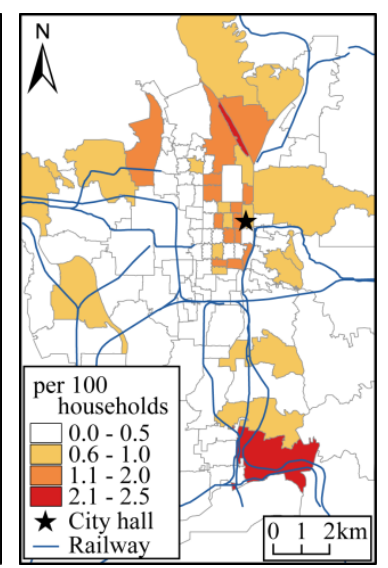

Kyoto (in 1937)

Figure 1. The distribution of telephone subscribers among company employees and executives in Tokyo, Osaka, and Kyoto in the mid-1930s.

The Second World War had two significant impacts on the white-collar workers in the major Japanese cities. First, although there was no severe damage only in Kyoto by the air raid, many of them lost their residences due to the fire and evacuation. Second, the decrease in young population by the conscription affected the whole Japanese society without any distinction between urban or rural areas.

Regarding the distribution of the white-collar workers in 1965, there were no significant impacts of WWII. From the mid1930s through 1965, the suburbanization of the white-collar workers in the three cities progressed further. The whitecollar workers living in the city center gradually decreased in Osaka and Kyoto. In fact, the war damage did not affect the urban structure on the residential differentiation, but it changed the urban landscape completely.

Since the distribution of white-collar workers' residences in the mid-1930s Tokyo, Osaka, and Kyoto appears to be consistent with that in 1925 and 1965, the telephone directory seems to be an effective source of information on office workers in small areas. In the future, we aim to analyze residences of all white-collar workers (e.g., clerical workers, professionals) using telephone directories.

We have assumed that the distribution of white-collar workers' residences in the 1930s (based on the telephone directories) was the first phase in the long-term transition of white-collar workers from 1925 to 1965 in Tokyo, Osaka, and Kyoto. The southwestern suburb of Tokyo, where many of the white-collar workers lived in 1965, began transforming into residential areas for white-collar workers since the mid-1930s. This was due to an increase in the supply of residential properties after the Great Kanto earthquake in 1923. On the other hand, the pressure of suburbanization was weaker in Osaka and Kyoto; hence, in 1937, the spatial distribution of white-collar workers in these cities had a less pronounced sectoral pattern than the distribution in Tokyo. However, between 1937 and 1965, the residential pattern of the whitecollar workers in Osaka and Kyoto began changing into a sectoral structure. 